\title{
Bone loss-related factors in tissue and bone level dental implants: a systematic review of clinical trials
}

\author{
Hamed Mortazavi ${ }^{1}$, Amin Khodadoustan ${ }^{2}$, Aida Kheiri ${ }^{3}$, Lida Kheiri ${ }^{4}$ \\ ${ }^{I}$ Department of Oral Medicine, School of Dentistry, Shahid Beheshti University of Medical Sciences, Tehran, \\ ${ }^{2}$ Member of Iranian Association of Periodontology, Private Practice, Tehran, \\ ${ }^{3}$ Student Research Committee, School of Dentistry, Shahid Beheshti University of Medical Sciences, Tehran, \\ ${ }^{4}$ Department of Oral and Maxillofacial Surgery, School of Dentistry, Islamic Azad University, Isfahan (Khorasgan) Branch, Isfahan, Iran
}

\begin{abstract}
J Korean Assoc Oral Maxillofac Surg 2021;47:153-174)
Dental implants are popular for dental rehabilitation after tooth loss. The goal of this systematic review was to assess bone changes around bone-level and tissue-level implants and the possible causes. Electronic searches of PubMed, Google Scholar, Scopus, and Web of Science, and a hand search limited to English language clinical trials were performed according to PRISMA (Preferred Reporting Items for Systematic Reviews and Meta-Analysis) guidelines up to September 2020. Studies that stated the type of implants used, and that reported bone-level changes after insertion met the inclusion criteria. The risk of bias was also evaluated. A total of 38 studies were included. Eighteen studies only used bone-level implants, 10 utilized tissuelevel designs and 10 observed bone-level changes in both types of implants. Based on bias assessments, evaluating the risk of bias was not applicable in most studies. There are vast differences in methodologies, follow-ups, and multifactorial characteristics of bone loss around implants, which makes direct comparison impossible. Therefore, further well-structured studies are needed.
\end{abstract}

Key words: Alveolar bone loss, Bone-implant interface, Bone resorption, Dental implants, Dental implant-abutment design

[paper submitted 2020. 10. 25 / revised 2021. 1. 19 / accepted 2021. 2. 5]

\section{Introduction}

Bone loss following tooth extraction is an important issue that requires rehabilitation ${ }^{1-4}$. Treatments such as removable or fixed prostheses do not typically provide satisfactory functional and aesthetic outcomes ${ }^{1}$. Endosseous implants with predictable long-term success rates (SCRs) have become popular in overcoming the limitations of conventional treatments and improving the quality of life $\mathrm{f}^{1,3,5}$.

Survival and SCRs of implants are related to surrounding bone quality, quantity, and preoperative mucosal tissue

\section{Lida Kheiri}

Department of Oral and Maxillofacial Surgery, School of Dentistry, Islamic Azad University, Isfahan (Khorasgan) Branch, University Blvd, Arqavanieh, Jey Street, Isfahan 81595-158, Iran

TEL: +98-9132748055

E-mail:Kheiri91@gmail.com

ORCID: https://orcid.org/0000-0001-9471-9902

(c) This is an open-access article distributed under the terms of the Creative Commons Attribution Non-Commercial License (http://creativecommons.org/ licenses/by-nc/4.0/), which permits unrestricted non-commercial use, distribution, and reproduction in any medium, provided the original work is properly cited.

Copyright (C) 2021 The Korean Association of Oral and Maxillofacial Surgeons. All rights reserved. characteristics ${ }^{2,6}$. Patient age, oral hygiene, presence of dental plaque and microorganisms, implant location and features, surgical procedure, and prosthesis type are statistically significant factors for $\mathrm{SCR}^{7}$. Moreover, marginal bone around implants is affected by various factors including smoking, periodontal disease, socket condition, healing after insertion, and implant abutment microgaps ${ }^{8}$.

Many studies have analyzed ways to improve implant features since the macrostructure, microstructure, and biomechanical design of implants affect marginal bone-level changes and subsequent tissue interactions ${ }^{1,2,4}$. Roughened hydrophilic implant surfaces enhance bone healing, osteogenesis, and bone-implant contact (BIC) by accelerating cell migration, proliferation, and differentiation ${ }^{4,9,10}$. SLActive surfaces have been created by coarse grit blasting and acid etching in order to promote fatigue strength with the mechanism of stabilizing blood clots in the defect area without affecting osseointegration ${ }^{1,4,11}$.

Two types of implants have been introduced based on their macrostructure characteristics: bone-level (BL) and tissuelevel (TL). BL types are placed with the neck of the implant 
at the level of the crestal bone and can cause marginal bone loss (MBL) following bacterial contamination or inflammation ${ }^{12,13}$. Therefore, the TL design has been proposed to eliminate inflammation and subsequent bone loss. However, it may cause a gray metallic shadow through the soft tissue because of the metallic tulip-shaped shoulder ${ }^{12,13}$. BL implants are the implant of choice in esthetic areas since they can be placed more apically and create a desired emergence profile $^{14,15}$. It has been reported that SLActive BL implants induce bone apposition ${ }^{4}$.

Implants are designed to be used as a one-piece or twopiece instrument. More crestal bone loss in two-piece implants may be due to microgaps at the implant-abutment interface for bacterial colonization of the implant sulcus or establishment of an adequate dimensioned biologic width (BW) to be associated with marginal bone resorption ${ }^{16,17}$. The implant-abutment microgap is possibly related to the precision fit between the implant components subsequent to the implant system design and the torque used to connect the components ${ }^{17}$. Researchers have attempted to introduce designs to eliminate the microgaps ${ }^{18}$. The gaps and the following disadvantages have been diminished using TL implants ${ }^{12,13}$. One-piece implants could provide a more effective seal against microbial leakage by reducing the size of the microgaps resulting in a reduction in inflammatory reactions around the implant-abutment interface and subsequent marginal bone resorption ${ }^{19}$. The abutment-fixture connection (AFC) is an important factor for the long-term stability of implants and hard and soft tissue due to the presence of microgaps $^{14,20}$. Therefore, the prevention of microbial leakage at the AFC is a major challenge for the construction of two-piece implant systems to minimize inflammatory reactions and to maximize peri-implant bone stability ${ }^{21}$.

The most common AFCs are external hexagonal, internal hexagonal, conical, and mixed ${ }^{17,21}$. All the connections exhibit a certain amount of microgaps and bacterial microleakage, although fewer are seen in the conical and mixed connection systems ${ }^{21}$. The most favorable results have been reported when implants with an internal Morse-taper connection have been utilized, resulting in minimal bacterial leakage to the threaded aspect of the AFC. However, dynamic loading increases the potential for such bacterial penetration ${ }^{17,21}$. Platform-switching has been introduced as a method to shift the stress inward and enhance hard tissue stability, papilla maintenance, and the soft tissue seal ${ }^{16,19,22-25}$. A study reported 0.7 $\mathrm{mm}$ versus $2.5 \mathrm{~mm}$ bone loss compared to the conventional connection design after 6 months of loading while the other design exhibited $0.12 \mathrm{~mm}$ versus $0.29 \mathrm{~mm}$ bone loss after one year $^{16}$. Another assessment demonstrated no bone loss after 2 years ${ }^{16}$. Until now, no implant system or connection design has been able to provide a perfect outcome at the AFC.

Minimizing bone loss both horizontally and vertically around implants, which is essential for good aesthetic outcomes of implant treatment, has been the most challenging issue in implantology. Therefore, the aim of the present systematic review is to review and compare BL changes after the insertion of BL and TL designs of implants and assess factors affecting bone loss.

\section{Materials and Methods}

This systematic review was conducted according to the Cochrane Handbook PRISMA (Preferred Reporting Items for Systematic Reviews and Meta-Analysis) guidelines.

All clinical trials which focused on BL change after the placement of BL or TL implants were included. The search was limited to English-language studies up to September 2020. Abstracts, letters, and reviews were excluded.

Type of participants: Any humans with edentulous regions in one or both jaws with BL and TL implant placements were included. Studies which focused on the soft tissue, aesthetic results, or did not mention bone resorption for each kind of implant separately were excluded.

Type of interventions: Studies that had used one or more BL or TL implants were included. Studies were excluded if they had focused on biomechanical features or the survival rate (SVR) of implants or had evaluated implant stability and micromotions.

Type of outcome measures: BL changes after implant insertion were reported by measuring MBL (mm), mean bone fill $\left(\mathrm{mm}^{2}\right)$, BIC (mm), new bone height $(\mathrm{mm})$, and mean bone level (mm).

Information sources: Our electronic database consisted of PubMed/MEDLINE, Google Scholar, Scopus, and Web of Science. Additionally, a hand search was performed to assess publications that were not electronically distinguished.

Search strategy: An electronic search was performed in order to select relevant studies using the following terms: "bone level implant", "tissue level implant", "bone level implant" AND/OR "tissue level implant", "bone/tissue level implant" AND "marginal bone loss", "bone/tissue level implant" AND "bone resorption", and "bone/tissue level implant" AND "marginal bone level change".

Study selection: Two independent authors conducted the 
search based on the aforementioned keywords. In addition, they carried out the initial screening of titles and abstracts from selected studies in accordance with the eligibility criteria. Any disagreement between the authors was resolved following a discussion with the third author (periodontist).

Data collection process: Review and data extraction were performed according to the PRISMA flow diagrams. Two authors also reviewed full texts of the articles and extracted all the data independently.

Data items: Results and data extracted from the included studies were classified in tables with the following columns: study type, study design, implant placement area, bone results, non-related bone results, measurement device, defect model, and follow-up.(Tables 1-3)

Risk of bias assessment: The criteria used for assessing the quality of the included studies was obtained from the Cochrane Center. The provided guidelines consisted of the following parameters: random sequence generation, allocation concealment, blinding of participants and personnel, blinding of outcome assessment, incomplete outcome data addressed, and selective reporting. The degree of bias was categorized as low risk, unclear risk, and high risk. The risk of bias was evaluated independently by two masked reviewers. All disagreements were resolved by consensus.

\section{Results}

After the initial search, 173 articles were obtained. Following the removal of duplicates and irrelevant studies, a total of 97 studies were selected. Full texts of the selected articles were screened and with respect to eligibility criteria, 59 studies that either were in vivo or had focused on soft tissue results, biomechanical features, or implant stability with no bone-related reports were excluded. Finally, 38 articles were included in our systematic review.(Fig. 1) Data were extracted and further classified in three separate tables.(Tables 1-3) Table 1 consists of 18 studies that used only BL implants and 10 articles that used TL implants were placed in Table 2. Table 3 comprises 10 studies that compared BL change results of both BL and TL implants.

Patient sex, age, and number: Among the included studies, 10 did not mention patient $\operatorname{sex}^{1,10,22,23,26-31}$. Between all the studies mentioning mean age, maximum mean ages in Tables $1-3$ were $65.8^{1}, 54.63^{32}$, and $60^{30}$, respectively, while minimum amounts were $33^{24}, 36^{28}$, and $39^{33}$ in order.

Comparing patient numbers in the studies, the highest number of patients in a single study was $881^{25}$ with the lowest being 13 in another study ${ }^{10,31}$. Only 2 studies did not indicate the number of patients ${ }^{22,28}$.

Implant numbers: Various implant numbers were reported. The highest and lowest implant numbers used in the studies were $908^{13}$ and $16^{9}$ in Table $1,1,692^{25}$ and $16^{34}$ in Table 2, and $337^{29}$ and $32^{31}$ in Table 3 , respectively.

Study design: Various methodologies had been used in the included articles. Seven studies utilized implants with SLActive surfaces ${ }^{1,9,10,13,22,28,35}$, while 7 studies focused on the platform switched implants effects ${ }^{5,23,24,36-39}$. Two articles inserted implants with both mentioned characteristics ${ }^{15,19}$.

Seven studies applied grafts in their surgical procedures $^{2,16,40}$ in which 4 of them indicated the use of autogenous bone grafts ${ }^{5,15,41,42}$. In addition, 10 studies mentioned guided bone regeneration (GBR) in their methods $3,8,9,19,20,25,26,43-45$.

Implant placement areas: In 10 articles, implants were inserted in the maxilla ${ }^{10,15,16,19,23,24,33,34,43,45}$, while 4 studies chose the mandible as the placement area ${ }^{1,6,28,31}$. In 22 studies, implants were inserted in both jaws ${ }^{2,3,5,8,13,20,25-27,29,30,32,35-42,44,46}$. Two studies did not state which jaw was used ${ }^{9,22}$.

Measurement devices: The majority of studies used only periapical radiographs to estimate bone resorption around the implants $3,6,9,13,15,16,19,22,27,33-37,39,43$. Four studies utilized conebeam computed tomography (CBCT) images ${ }^{10,28,29,44}$, while 3 studies used panoramic images ${ }^{1,32,42}$. A combination of panoramic plus periapical images and $\mathrm{CBCT}$ plus periapical images were used in 6 studies $^{2,5,24,25,30,40}$ and 4 studies $^{31,38,45,47}$, respectively. One article evaluated MBL through the help of CBCTs, panoramics, and periapical images ${ }^{8}$, while another used panoramics, periapicals, and computed tomography (CT) scan images 5 . One study reported a radiological device to measure bone levels, but did not provide specifics ${ }^{20}$. Only one study used a morphometric method ${ }^{26}$, while one did not mention the measurement device ${ }^{23}$.

Follow-ups: Follow-up duration varied widely. In Table 1 , the shortest and the longest follow-ups were one month ${ }^{43}$ and 5 years $^{8}$, respectively; in Table 2 , these values were 3 months ${ }^{28}$ and 15 years $^{32}$, respectively. The longest period of follow-up was 7.8 years $^{33}$, while the shortest period was 3 months ${ }^{31}$ among the studies that used both BL and TL implants.

Bone results: Bone status after implant insertion varied. A large number of studies indicated bone loss $5,6,16,19,20,22,24,25,27,33,39,40-43$. MBL and BL changes were presented in 13 studies $^{2,5,8,15,24,25,28-31,36,38,47}$ and 11 studies $^{1,3,9,15,22,23,32,34,37,42,45}$, respectively. Other bone results involved reports of $\mathrm{BIC}^{36}$ and distances from implant shoulder 


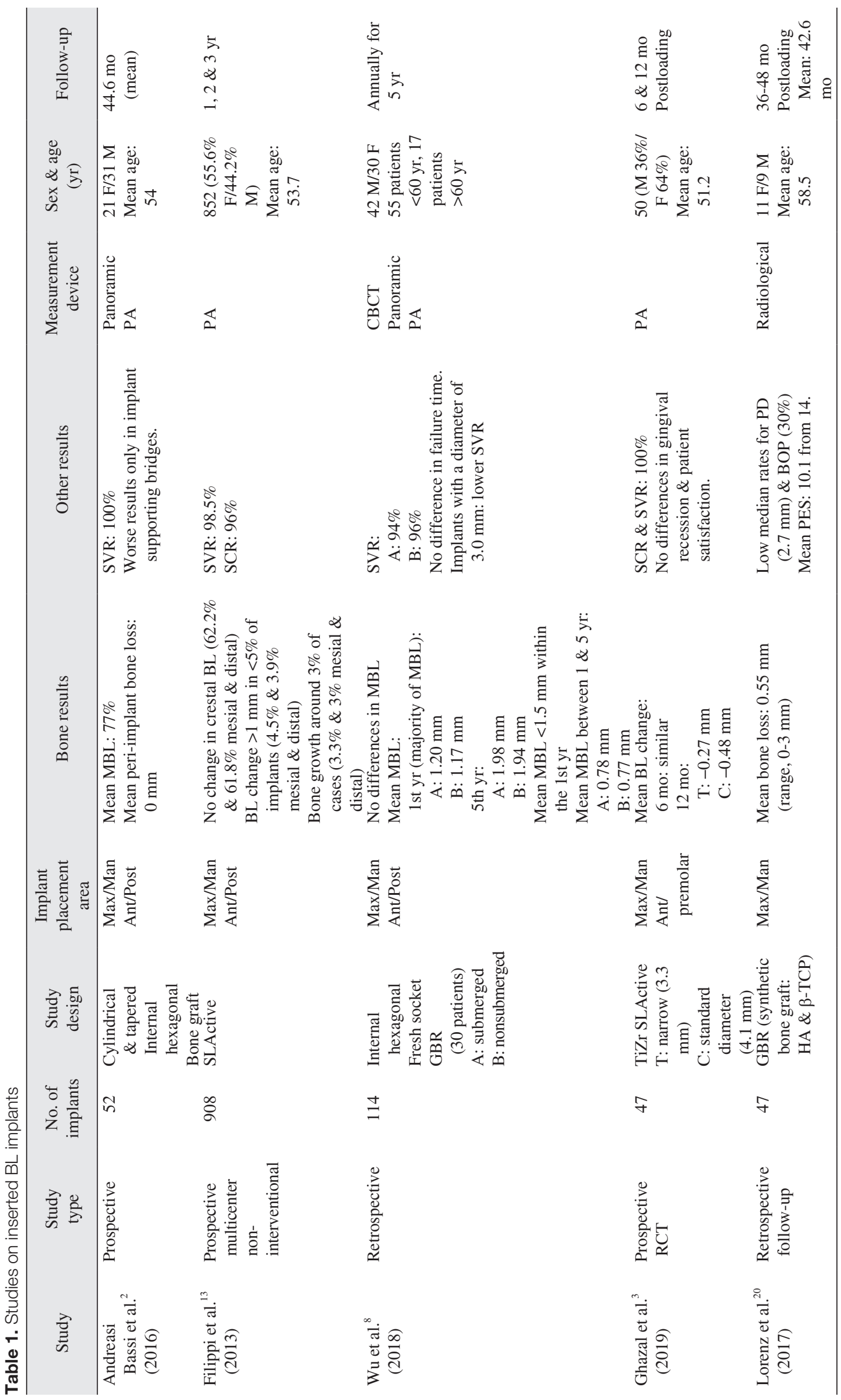




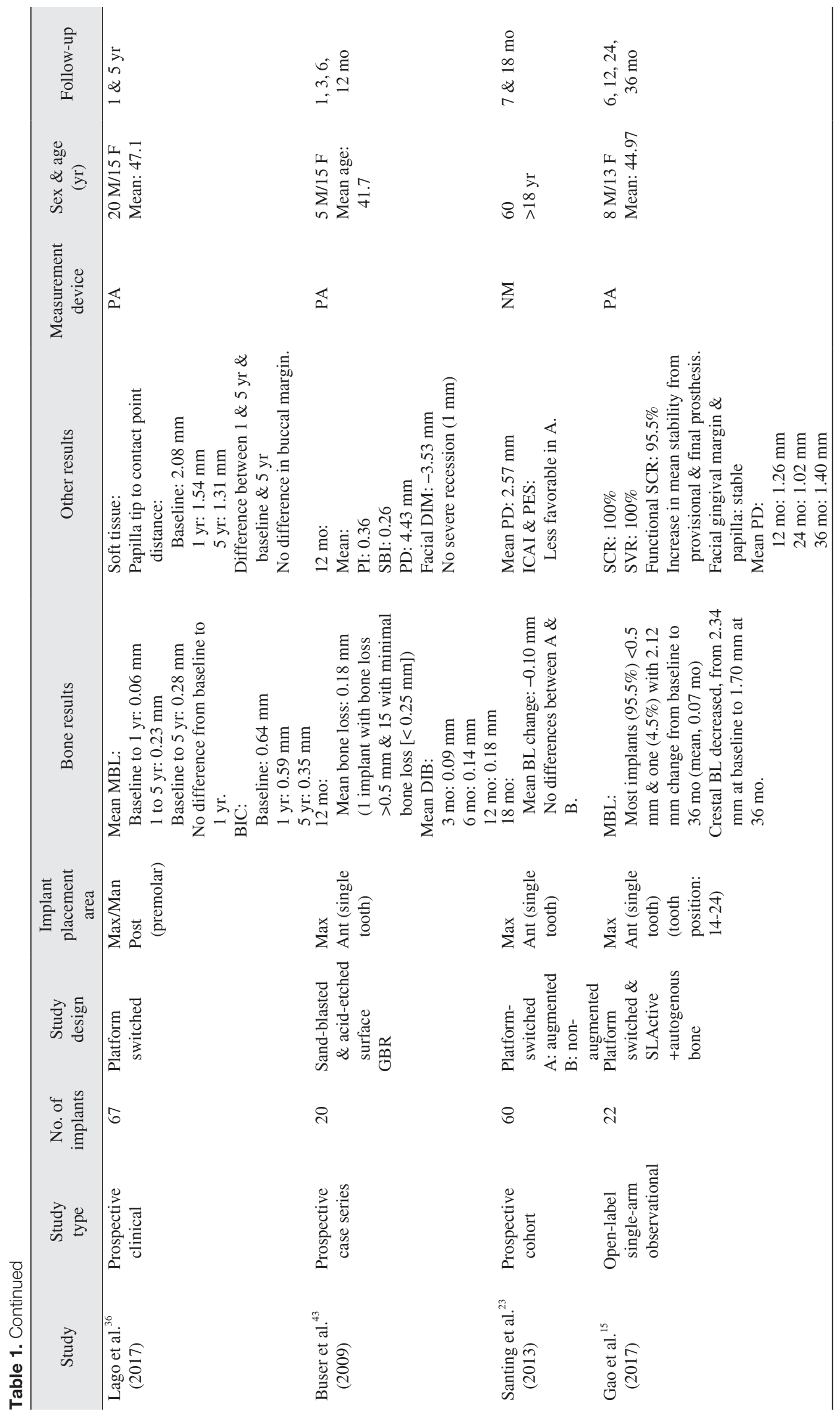




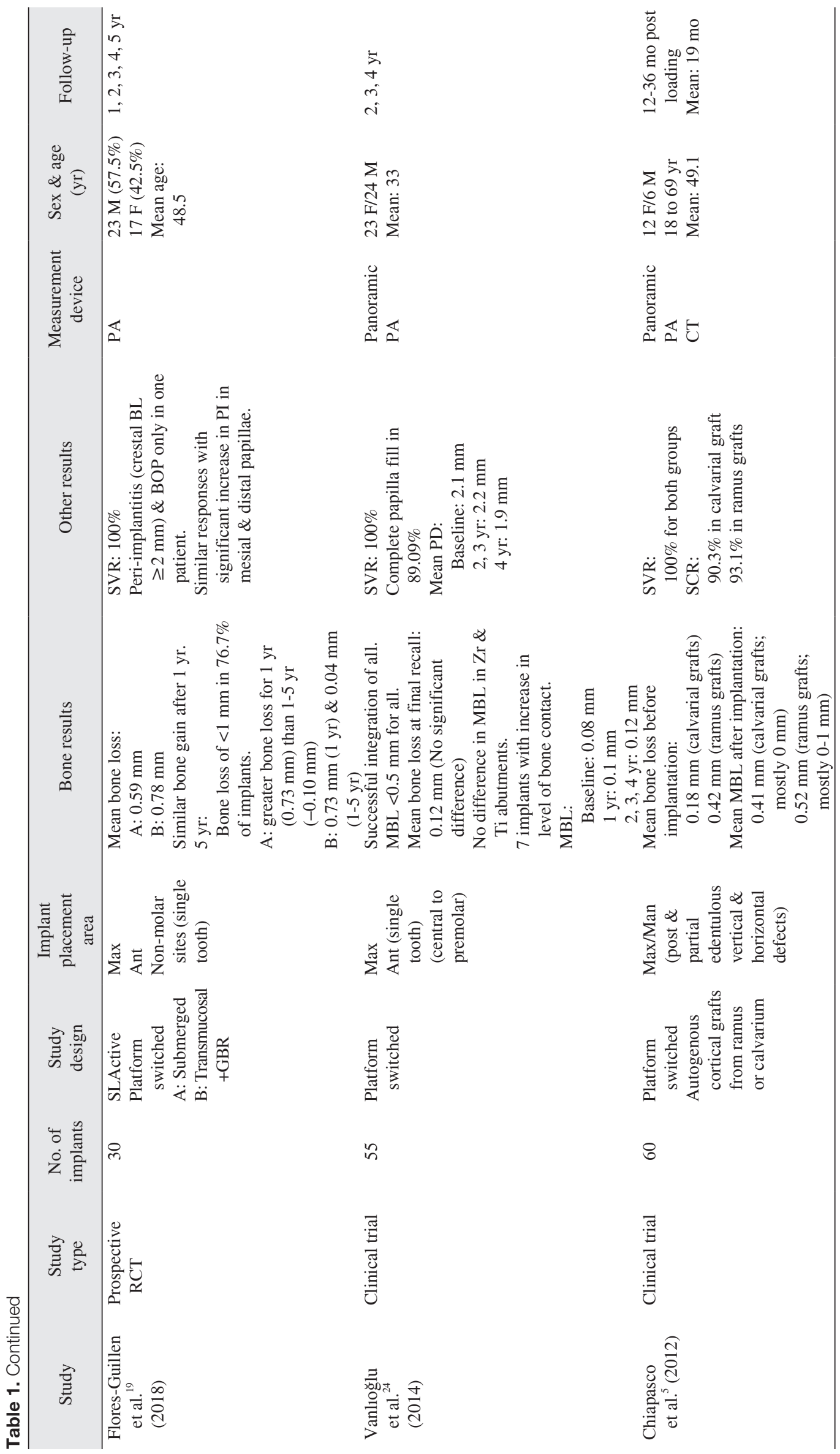




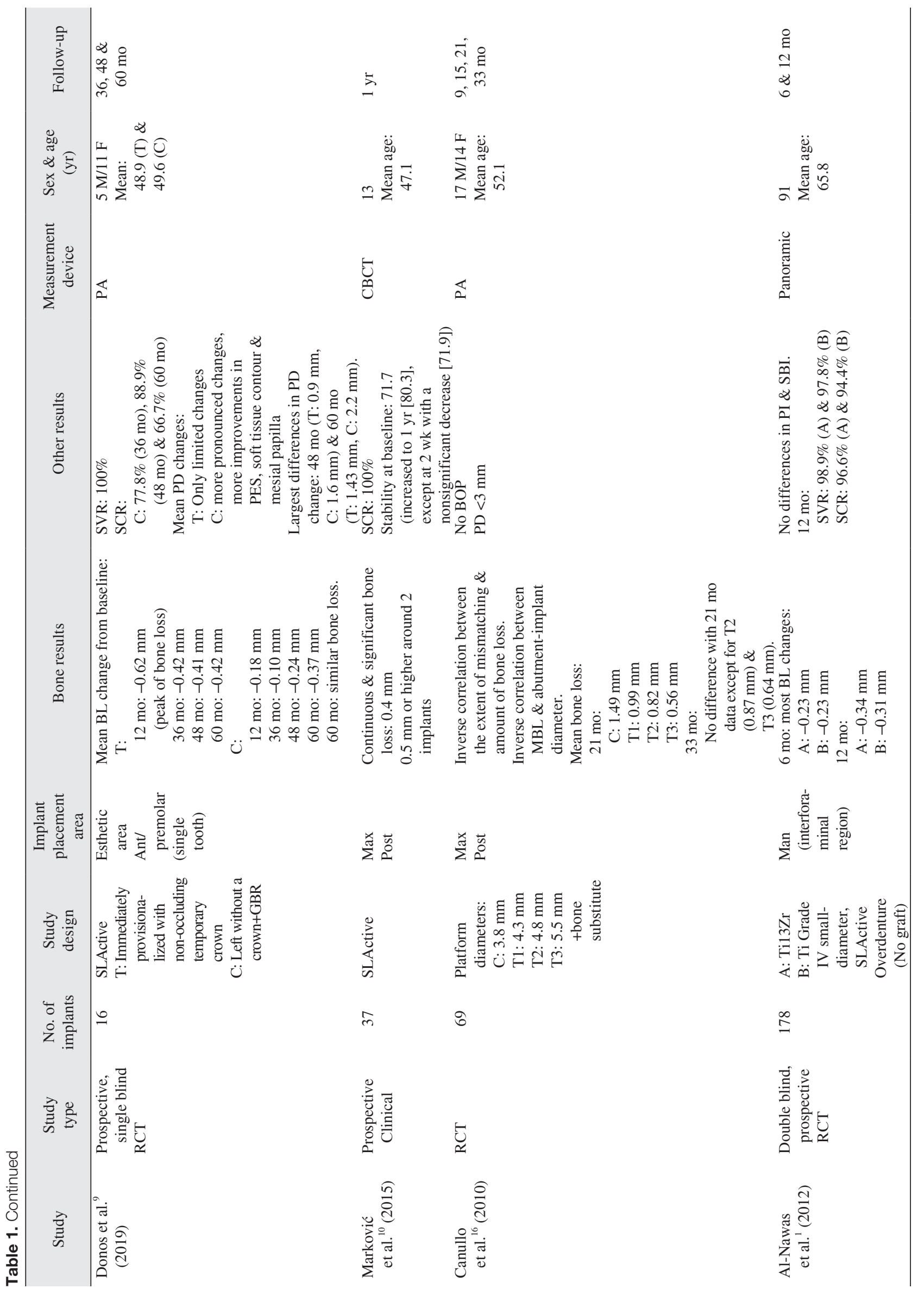




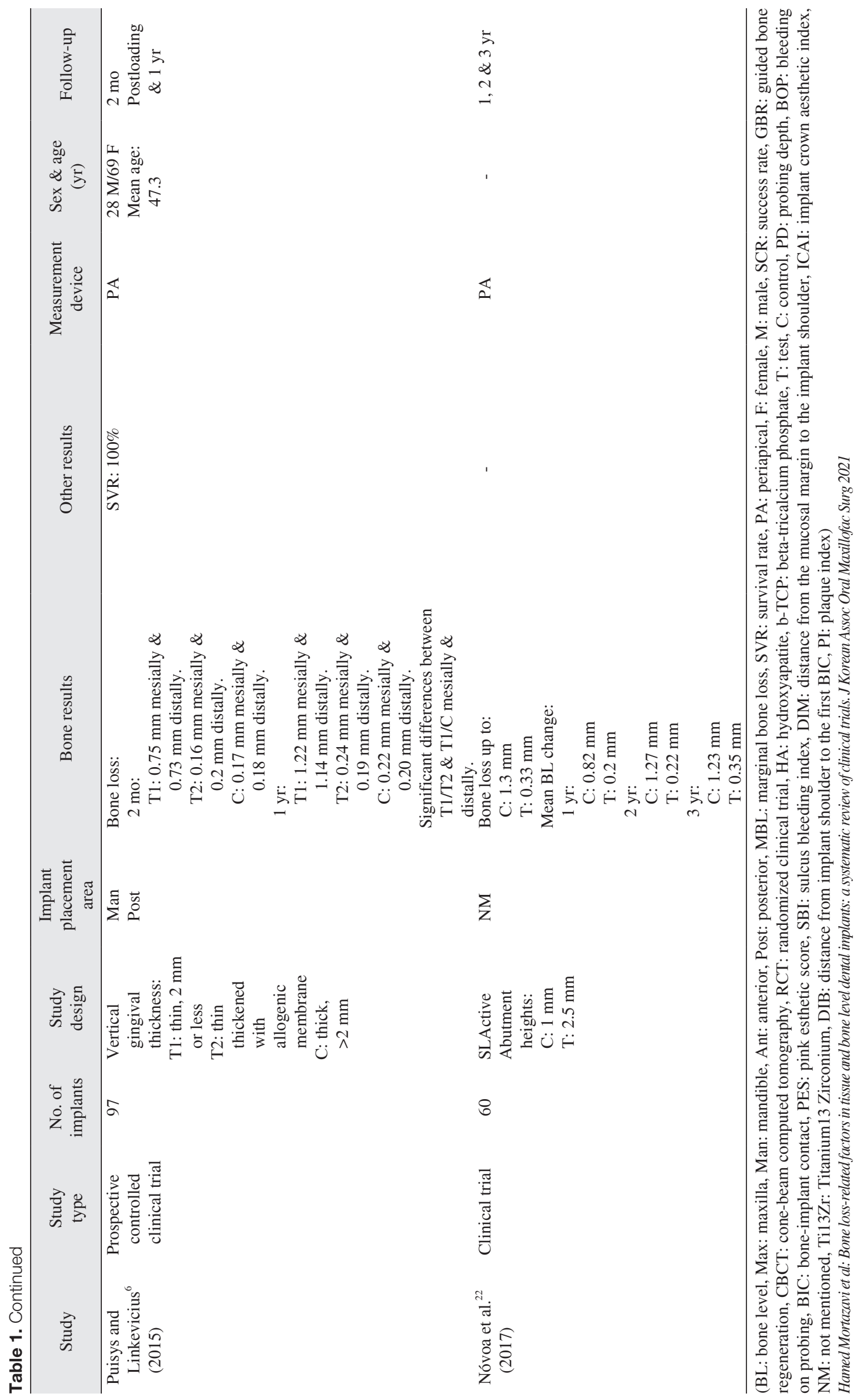




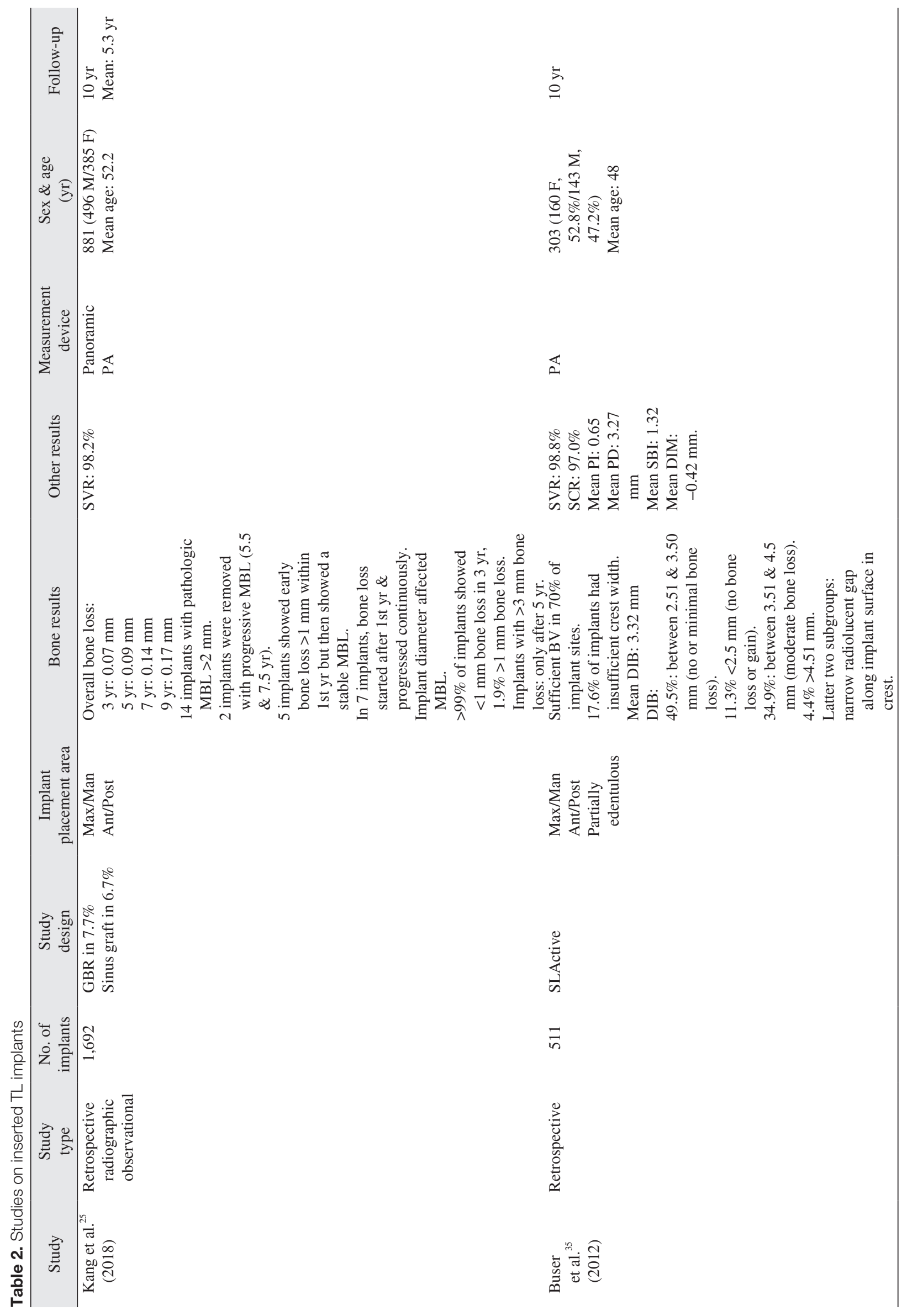




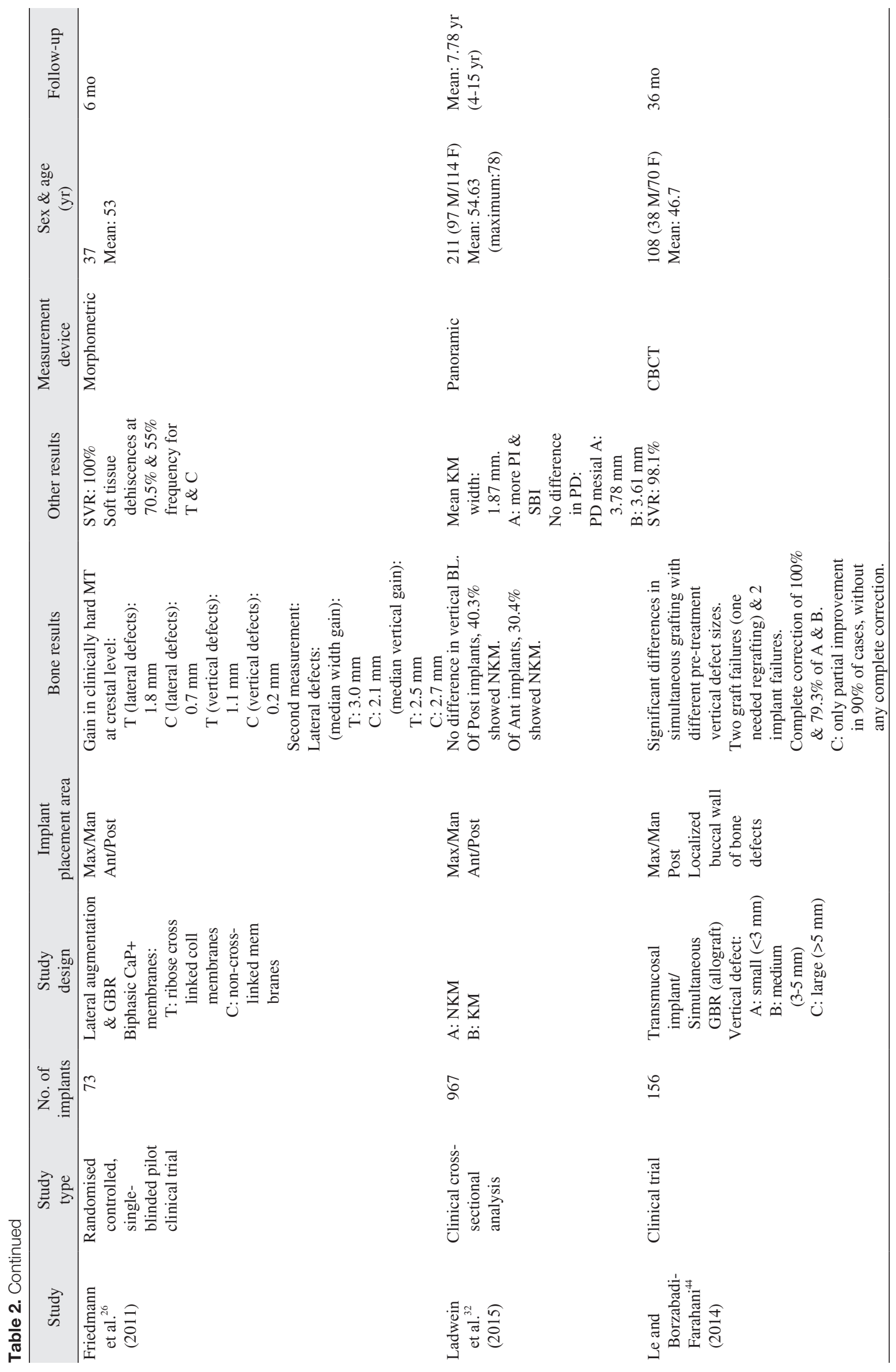




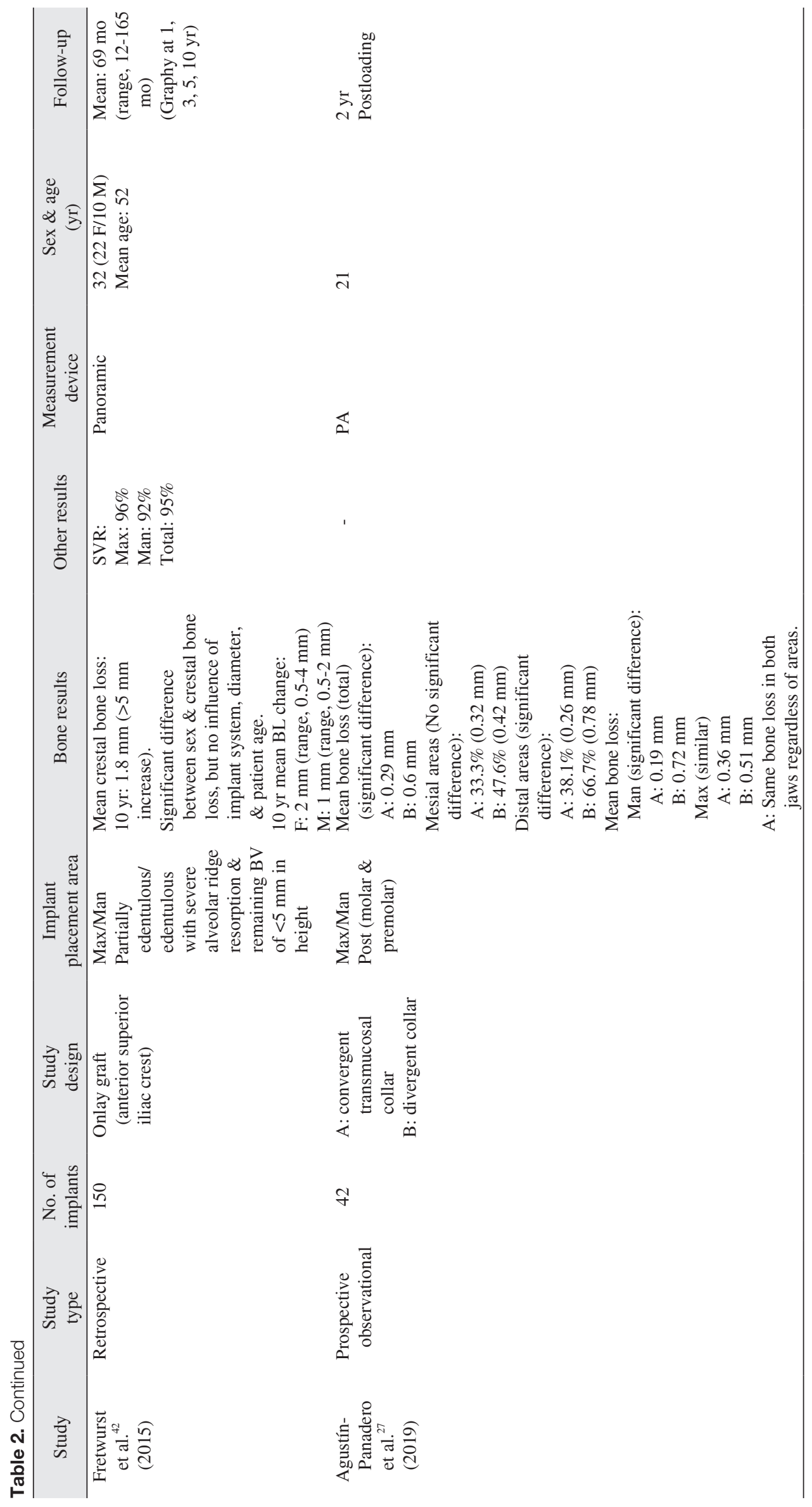




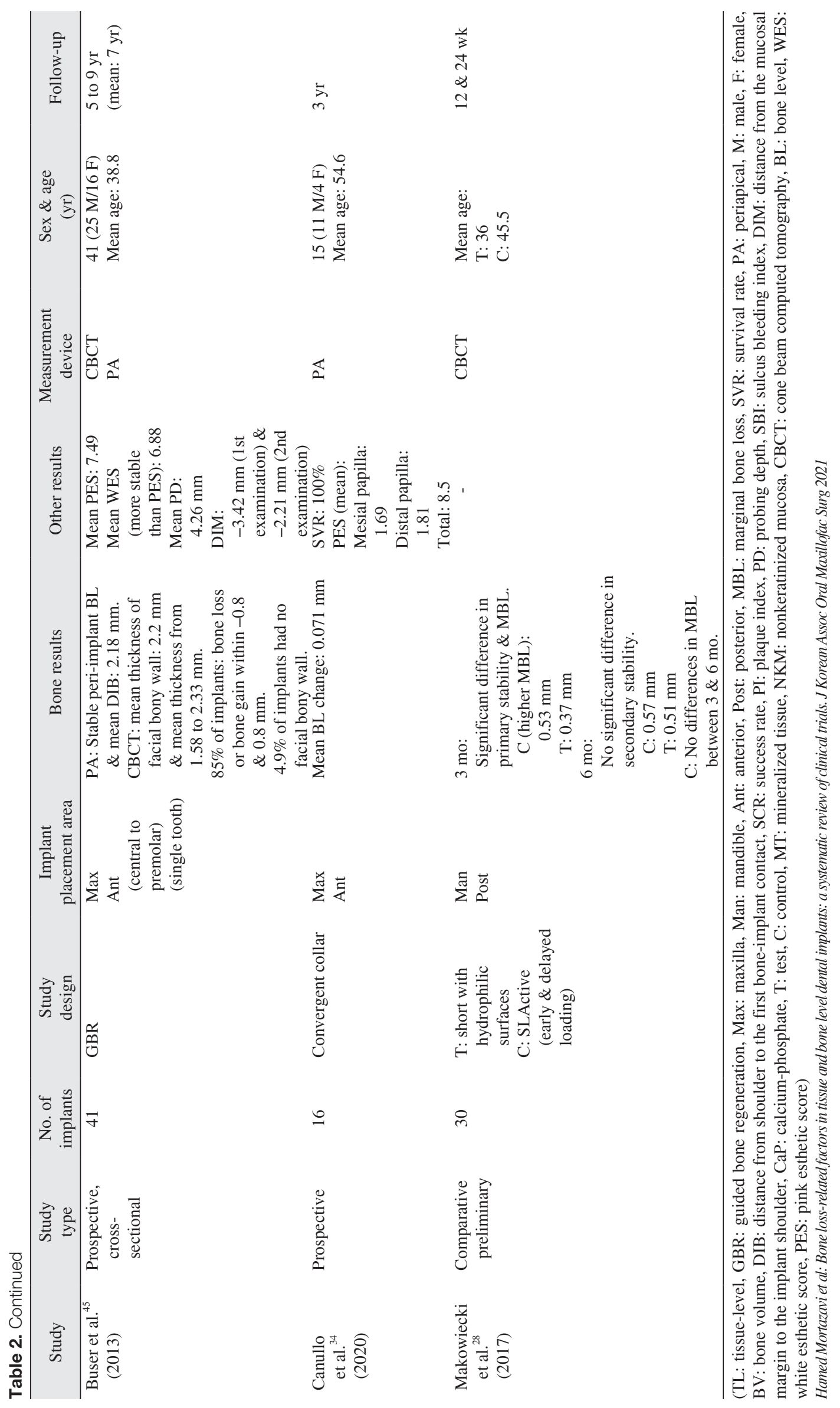




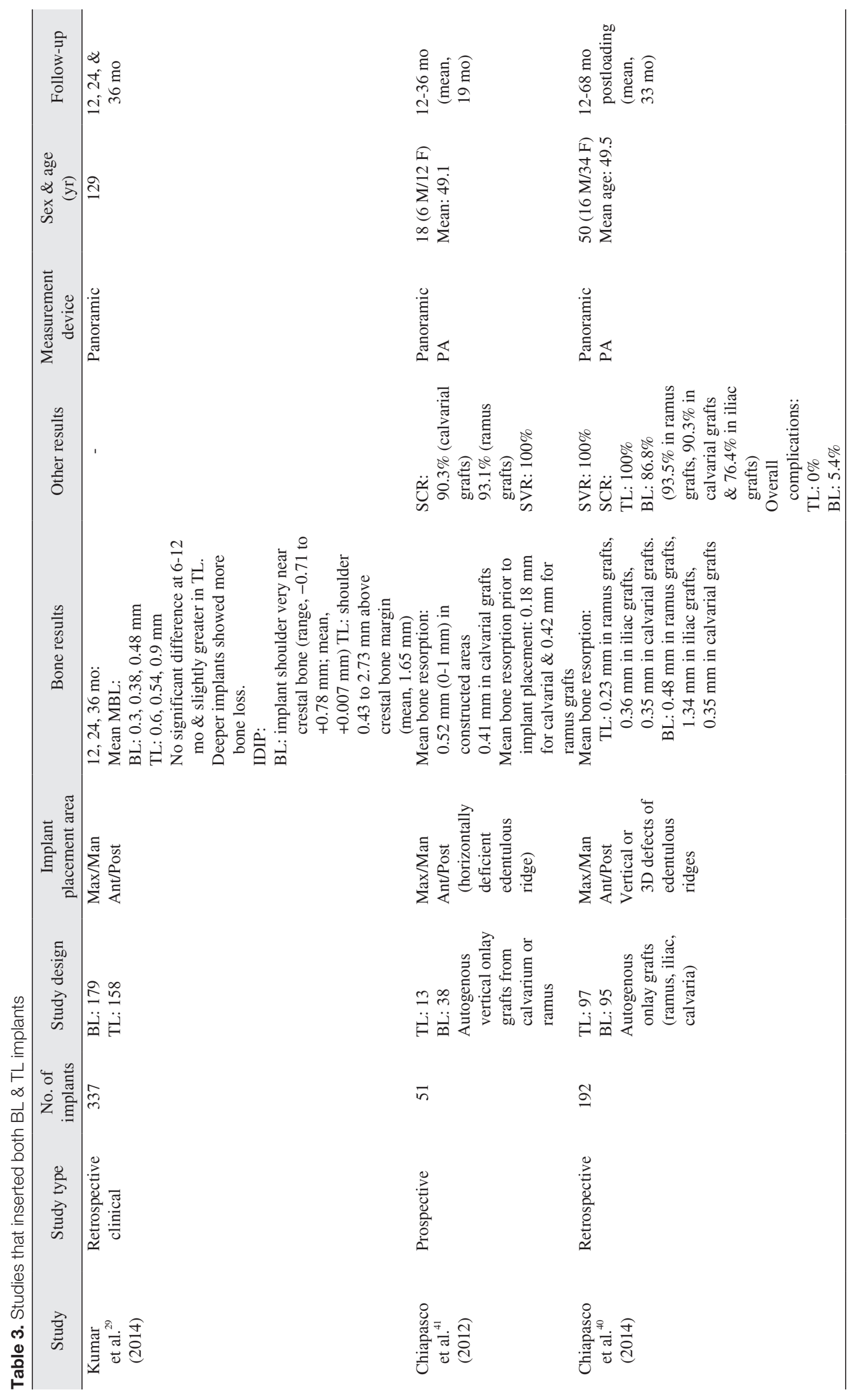




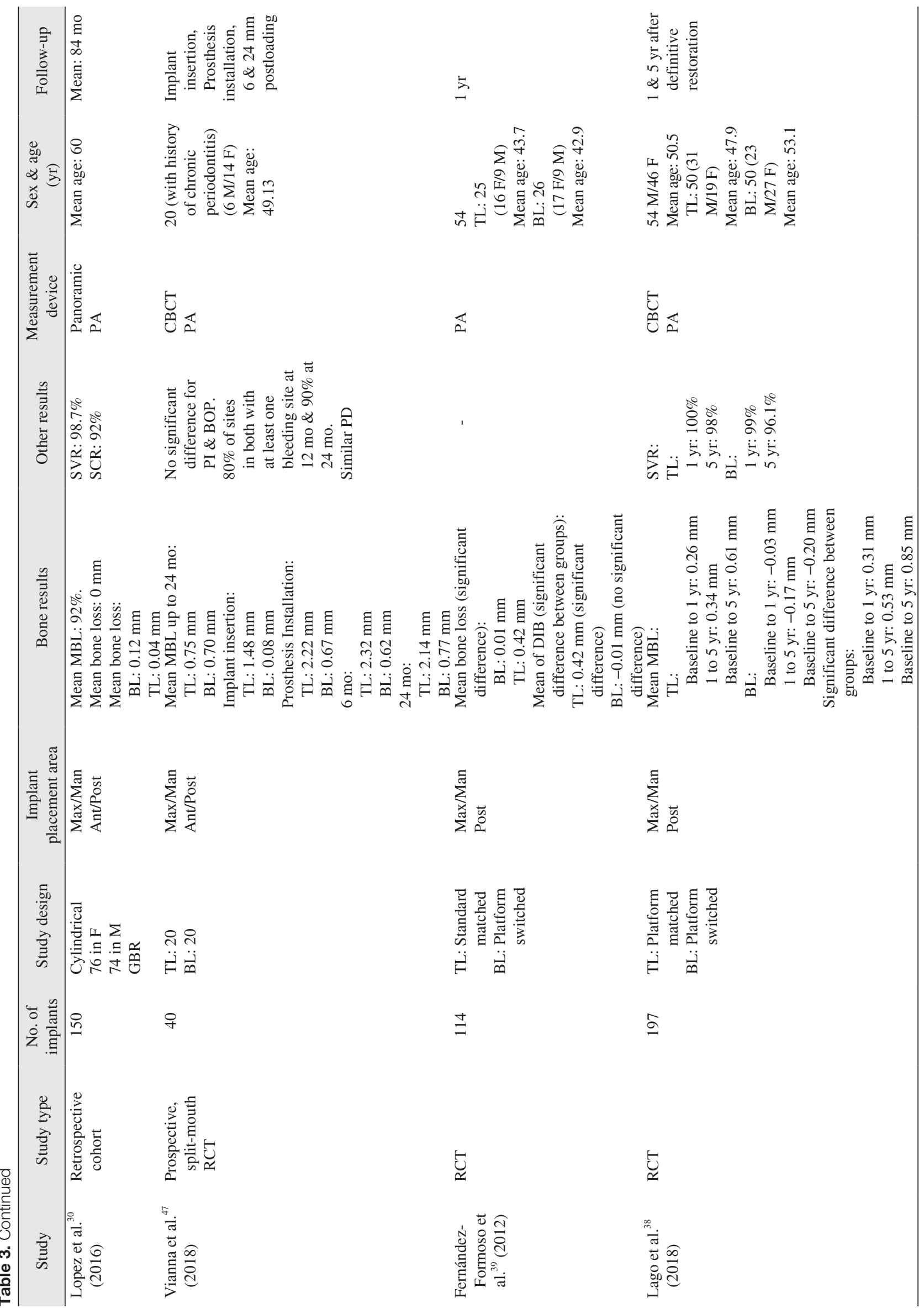




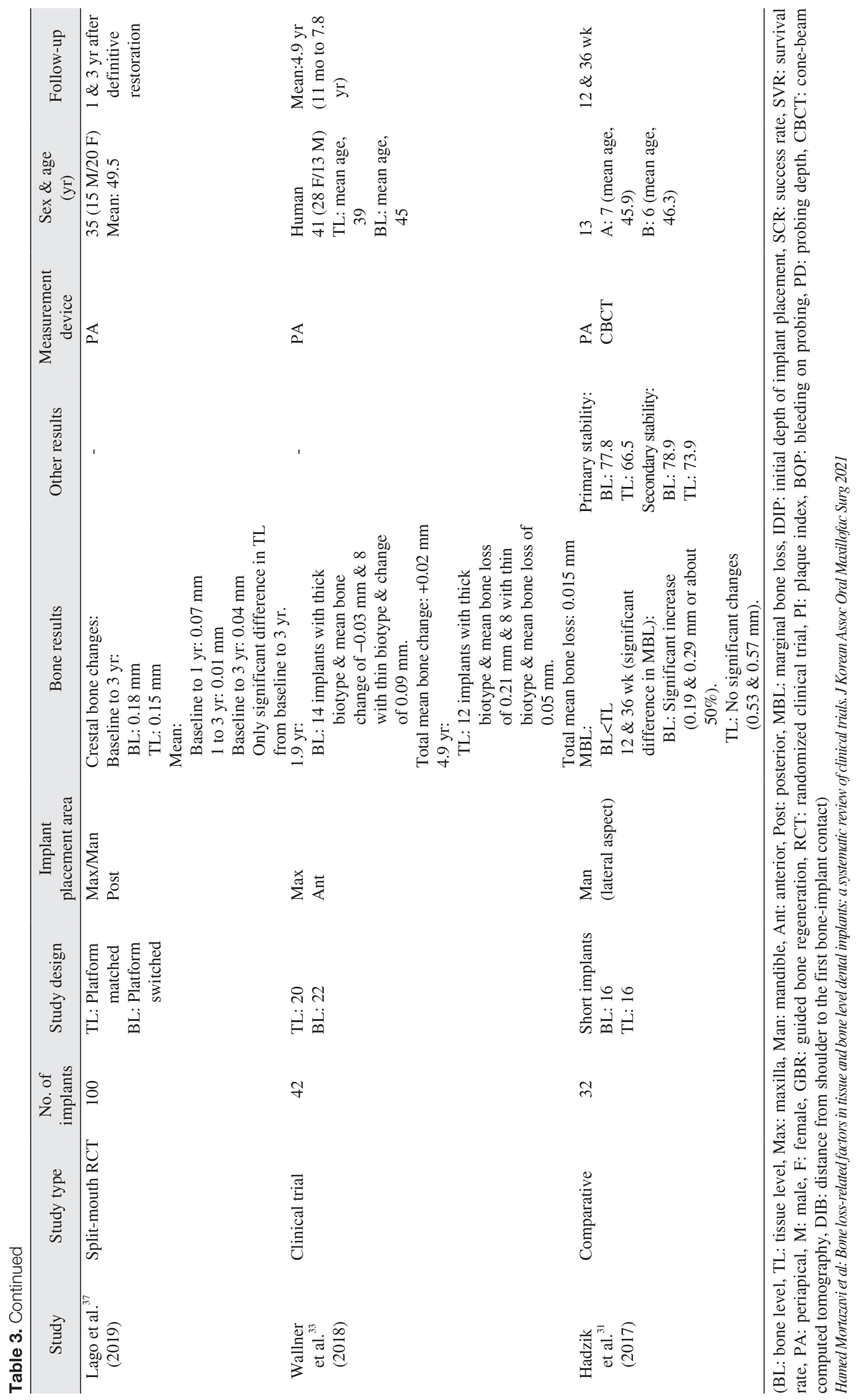




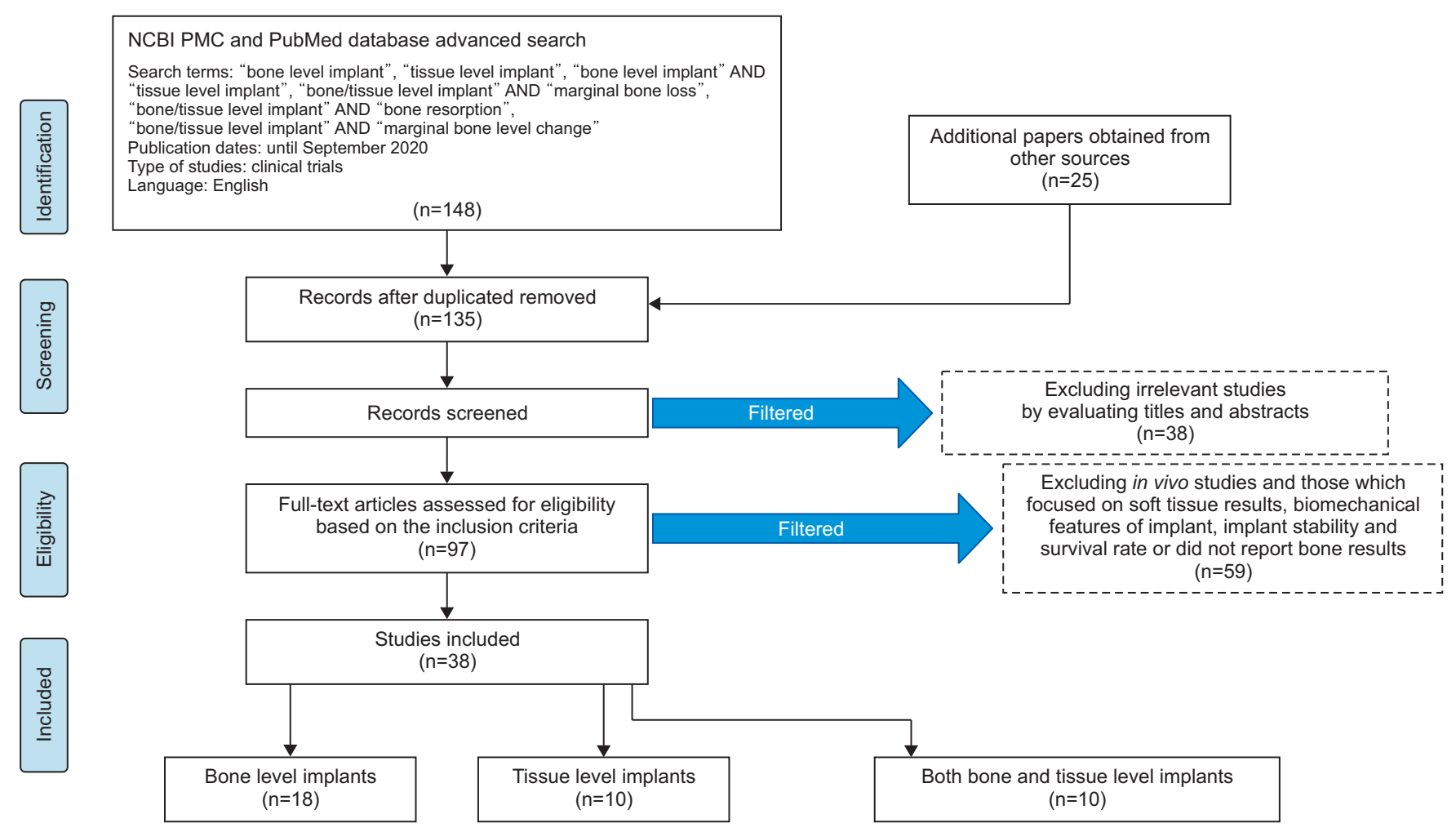

Fig. 1. Search strategy flowchart.

Hamed Mortazavi et al: Bone loss-related factors in tissue and bone level dental implants: a systematic review of clinical trials. J Korean Assoc Oral Maxillofac Surg 2021

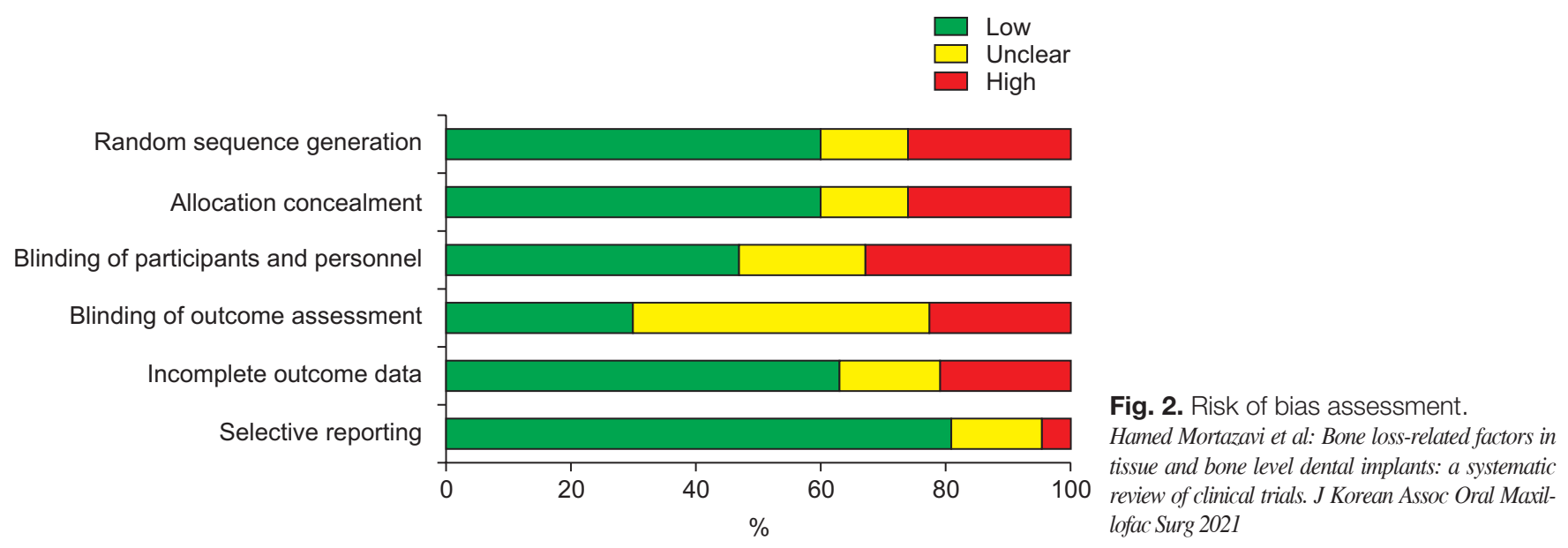

to the first BIC (DIB) $35,39,43,45$. Two studies reported both MBL and mean bone loss ${ }^{25,30}$. In one article, hard mineralized tissue at the crestal level was evaluated ${ }^{26}$, while another study reported the correction percentage of vertical defects after GBR and TL implant insertion ${ }^{44}$.

Non-related bone results: Ten studies reported $\mathrm{SVR}^{2,6,8,19,24-26,36,42,44}$, while one article mentioned only $\mathrm{SCR}^{10}$. Both SVR and SCR were reported in 10 studies ${ }^{1,3,5,9,13,15,30,35,40,41}$. Other outcomes included reports of probing depths (PD) in 10 studies $^{9,16,20,23,24,32,35,43,45,47}$, plaque index (PI) in 4 studies ${ }^{1,32,35,43}$, bleeding on probing (BOP) in 2 stud- ies $^{20,47}$, and pink esthetic scores (PES) in 5 studies $^{9,20,23,34,45}$.

Risk of bias assessment: The evaluation of risk of bias is presented in Fig. 2 and 3. For 23 studies, randomization and blinding of participants, personnel, and outcome assessments were not applicable. Therefore, among 15 articles, 60\%, 47\%, and $30 \%$ of studies exhibited low risk in selection bias, performance bias, and detection bias, respectively. In relation to attrition bias and reporting bias, the majority of the studies showed no incomplete data or selective data reporting.(Fig. 2, 3) 


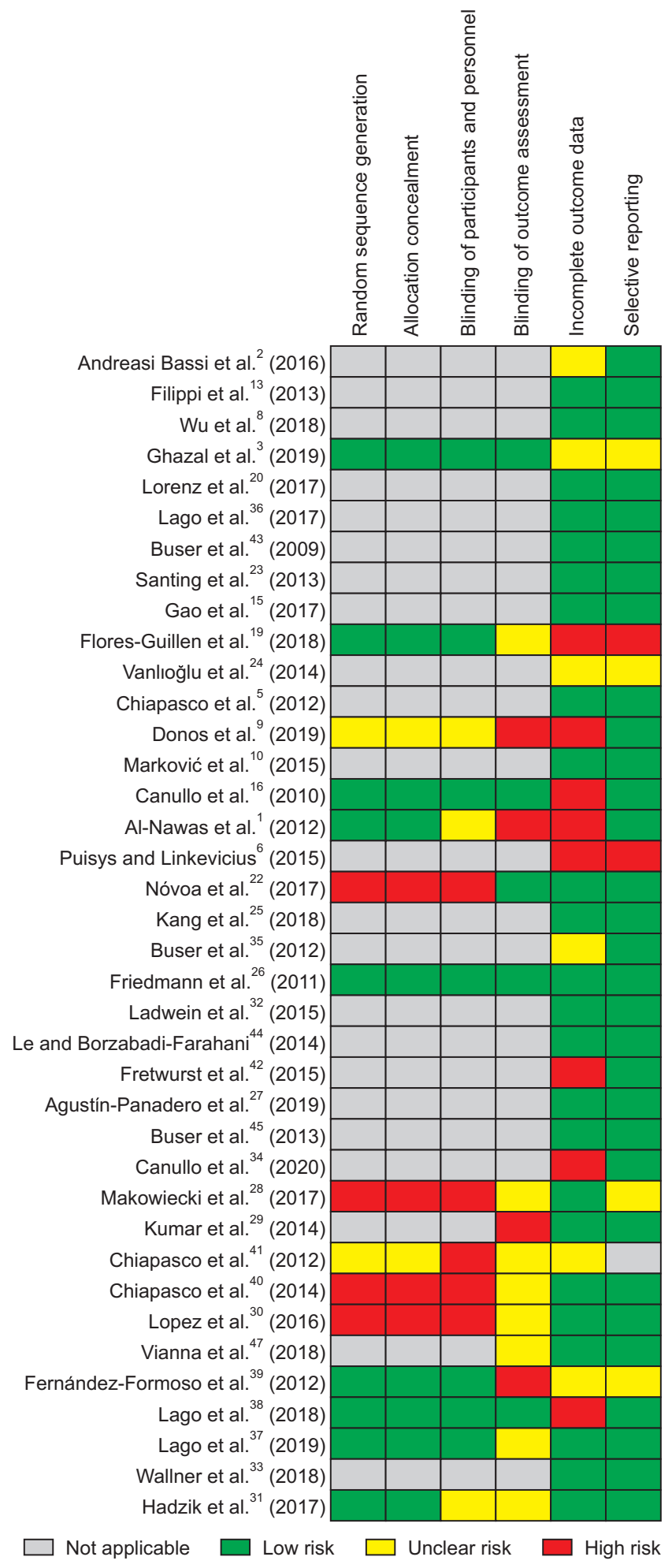

Fig. 3. Risk of bias assessment.

Hamed Mortazavi et al: Bone loss-related factors in tissue and bone level dental implants: a systematic review of clinical trials. J Korean Assoc Oral Maxillofac Surg 2021

\section{Discussion}

Although implant placement is the preferred treatment method for tooth loss, the reason for MBL remains controversial. MBL induces pocket formation and affects peri-implant tissue health ${ }^{24}$. In this review, parameters related to BL change after implant insertion are discussed in detail based on comparison of the included studies.

\section{Patient-related factors}

Individual differences: Significantly more MBL has been reported in females after 10 years, which may depend on differences such as factors influencing bone physiology and sex steroid hormones that provide harmony between bone formation and resorption with alterations in osteoclastogenesis and osteoblastogenesis ${ }^{42}$. Age and sex varieties may have an impact on autologous bone grafts ${ }^{43}$. Other factors such as smoking, periodontitis, and infection in sockets should be excluded in order to increase the homogeneity and reliability of the results of the clinical trials ${ }^{8}$.

Bone quality and quantity: Implant insertion in severely resorbed ridges may lead to more failures ${ }^{2}$. BL implants were successful in low-density bone after early loading protocols ${ }^{10}$. Interestingly, Marković et al. ${ }^{10}$ suggested that bone quality had no significant effect on the SVR of nonstructured and hydrophilic implants ${ }^{48}$. Lower primary stability and higher secondary stability have been evidenced in bone with lower density. However, no significant difference in secondary stability was reported by Makowiecki et al. ${ }^{28}$, which may be due to the differences in implant type and bone density. In their study, implants with more aggressive threads were inserted in bone type D1 as a study group and in bone type D2 as a control group. Maintaining a definite conclusion about the effect of bone density on implant stability remains difficult ${ }^{48}$.

Soft tissue type and thickness: When the preoperative situation is compromised and the patient is realistic, the patient may be satisfied with the final result even when the outcome of an objective aesthetic index is poor ${ }^{23}$.

Preoperative mucosal tissue thickness may be a major etiology in crestal bone $\operatorname{loss}^{6}$. According to Puisys and Linkevicius $^{6}$, implant design and surface treatment does not have a significant impact on crestal bone levels if mucosal tissue is thin during implant insertion. Therefore, it can be hypothesized that when initial mucosal thickness is insufficient, BW with bone loss forms before loading. Therefore, a certain minimum width of peri-implant mucosa may be required ${ }^{6,22}$. 
Although a high degree of satisfaction was observed in all subjects in whom allogenic membranes were used for vertical thickening of the soft tissues, thickened soft tissue may become thinner with time ${ }^{6}$. If mucosal tissue is $\leq 2 \mathrm{~mm}$, significant bone loss may occur ${ }^{6}$. Soft tissues with thin biotypes exhibited more desirable outcomes even though thick, soft tissues have been more resistant to inflammation and trauma due to the different blood supply to the bone ${ }^{33}$. It has been suggested that BL implants be used in areas with transparent soft tissue to obtain better esthetic results ${ }^{33}$. Wallner et al. ${ }^{33}$ reported negligible bone loss when a steady state has been achieved after the first phase of remodeling. They proposed that neither soft tissue type nor implant design affects periimplant bone levels ${ }^{33}$.

\section{Implant-related factors}

Implant type: BL implants provide more varieties of gingival formers during surgery with the margin of the abutment being adjusted at the time of prosthetic treatment ${ }^{8}$. In the study by Gao et al. ${ }^{15}$, after 6 weeks, surrounding bone loss was observed in all implants except for one that was placed above the alveolar crest shoulder. Interestingly, Gao et al. ${ }^{15}$ noticed not only $<0.5 \mathrm{~mm}$ bone resorption at the crestal level of BL implants which was less than other reports, but also 3 cases with bone gain. Despite BL types which are placed at the crestal level with BW being set in a more apical position, TL implants reduce the recession of barrier epithelium and connective tissue depending on its position to the bone crest $^{22}$. In addition, TL implants locate the AFC transmucosally, which demonstrates minimal bone alteration, but with compromising soft tissue esthetics because of the possibility of becoming visible. Therefore, BL implants are used more frequently in esthetic areas ${ }^{19,27}$. On the other hand, TL implants with a convergent collar exhibited proper esthetic outcomes and stable hard and soft tissues during follow-ups in the anterior maxilla which can increase tissue thickness with being directly cemented on the implant neck and providing space for the connective tissue section of the supracrestal tissue attachment ${ }^{27,34}$. Another advantage of the TL type is the ability to be detected easier during osseointegration with more favorable handling ${ }^{8}$.

Implant platform design: Crestal bone loss might be due to microgaps at the AFC for bacterial colonization of the implant sulcus or establishment of an adequate dimensioned BW to be associated with MBL at regions with a thin mu$\operatorname{cosa}^{34}$. This biological process is altered by repositioning the outer edge of the AFC horizontally more inwardly and away from the outer edge of the implant platform leading to the introduction of the platform-switching design, in which a smaller-diameter prosthetic component is connected to a larger-diameter implant platform ${ }^{39}$. The impact of platform switching on long-term crestal bone preservation remains controversial $^{19}$. Canullo et al. ${ }^{16}$ introduced the relationship between platform switching design and the amount of MBL that could be attributed to a wider space for the horizontal repositioning of $\mathrm{BW}$ and/or a better distribution of loading stress at the $\mathrm{BIC}^{9,13,16,20}$. The limitation of the study was that it only involved information on altering crestal mesial and distal bone loss especially vertically, not buccally and palatally $^{16}$. Vanlıoğlu et al. ${ }^{24}$ demonstrated that BL implants with platform switching resulted in minimal bone resorption at the crestal level during functional loading. However, some implants exhibited an increase in bone height. On the other hand, BL implants with the platform switched design demonstrated a negative influence on crestal bone levels in comparison to TL implants ${ }^{41}$. Despite the evidence of higher crestal bone stability in platform switched BL implants by Fernández-Formoso et al. ${ }^{39}$, higher SVR in TL implants with the platform matched design compared to platform switched BL implants was shown in another study (98\% vs $96.1 \%$ after 5 years $)^{39,49}$. Comparing BL and TL implants with nonplatform switched designs placed in the same graft type, similar SVR and peri-implant bone resorption were observed ${ }^{5,41}$. Less MBL has been demonstrated in Astratech implants with platform switched designs compared to Straumann TL implants after 12 and 36 weeks ${ }^{31}$. Therefore, long-term studies evaluating the clinical efficacy of platform switched designs are still necessary ${ }^{23,33,36}$.

\section{Treatment procedure and follow-up related factors}

Bone augmentation: The graft type seems to be the most important factor influencing graft resorption ${ }^{5,41}$. More bone resorption has been shown in cancellous bone which could be harvested from the iliac ${ }^{5,41}$. Demineralized bovine bone mineral (DBBM) granules will not be resorbed during the natural bone remodeling process and thus will help maintain the dimensions of the facial bone wall over time ${ }^{45}$. Synthetic bone substitute material induced significantly higher vascularization than xenogenic bone, but after 6 months, new bone formation was not different ${ }^{50}$. In the study performed by Le and Borzabadi-Farahani ${ }^{44}$, mineralized allograft provided sufficient strength and shape in $61 \%$ of cases. 
Similar implant stability and peri-implant bone changes were evidenced using the same BL implants (Astratech) with one study in fresh sockets and the other with $\mathrm{GBR}^{20}$. Likewise, Fretwurst et al. ${ }^{42}$ found similar BL changes in implants placed in both augmented and non-augmented areas. Buser et $\mathrm{al}^{45}$ did not demonstrate change in DIB overtime and showed that GBR successfully established a facial bony wall in $95 \%$ of patients that was maintained for a mean of 7 years.

Less favorable esthetic outcomes were demonstrated in augmentation areas, which may be due to imperfect preoperative situations or the formation of scar tissue. However, no significant differences were reported in marginal BL change $^{23}$. Submerge techniques plus bone augmentation prevent overloading and bacterial contamination ${ }^{8}$.

Choosing the best alveolar bone grafting technique remains a challenge. Bone graft shrinkage may occur following remodeling. Therefore, it is advised to overcorrect the augmentation site and use a vertical incision in the flap to advance the flap coronally and support the graft ${ }^{44}$. Grafting at the time of implant insertion reduces the number of invasive procedures and treatment time ${ }^{44}$.

Location of the crestal portion of the implant: The crestal positioning of the implant's rough surface has been correlated with a greater maintenance of peri-implant bone compared to subcrestal positioning ${ }^{22}$. The supracrestal location of AFC limits bacterial access to the attachment and reduces the inflammatory response from bacterial contamination. Therefore, less MBL occurs during early phases ${ }^{16,27}$. Kumar et al. ${ }^{29}$ demonstrated more MBL in deeper implants, which may depend on more stress distribution on the crestal bone and greater distance of the inflammatory infiltrate to the crestal bone. It is possible to place TL implants at greater depth ${ }^{33}$. On the other hand, less bone loss was reported in BL implants compared TL implants, but this was not significant, while in another study, significant lower MBL was observed in TL implants, which may be due to longer follow-up periods ${ }^{29,47}$.

Implant placement protocol: MBL after surgical trauma is accepted particularly in the submerging protocol of BL implants ${ }^{15}$. Implants can be inserted in 3 ways: immediate, early, and late ${ }^{43}$. Controversies exist in the hard and soft tissue results of immediate implant placement ${ }^{43}$. Many immediate implants with recession have no facial bony wall in the long term, even though immediate placement is only recommended in patients with low risk factors in the placement area ${ }^{43,45}$. Due to the lack of a facial bony wall around two implants, these two have no osseointegration in the facial aspect ${ }^{45}$.

Loading protocol: Immediate placement containing func- tional and non-functional (1 week), early (1-2 weeks), and conventional (more than 2 months) loading are known as the loading protocols ${ }^{9,24,43}$. In contrast to previous studies, immediate loading exhibited a tendency for better long-term implant $\mathrm{SCR}^{9,51}$. Even though nonfunctional loading helps diminish early overload, similar MBL and implant failure were reported between these two types of immediate loading $^{9,24}$. Successful functional early loading was reported without an increased risk of failure despite low bone density ${ }^{10}$. Early loading of platform switched BL implants is associated with minimal MBL and successful peri-implant mucosal architecture $^{24}$. It has been demonstrated that modified surface topography makes immediate or early loading possible even in areas of lower bone quality ${ }^{9,10}$.

Radiography: Although radiography is the most widely used method to measure remaining bone height, distortion, superimposition, artefacts, and magnification are several known shortcomings $\mathrm{s}^{27,52}$. CBCTs offer excellent image quality with diminished radiation exposure compared to $\mathrm{CT}$ scans $^{45}$. Despite the proper accuracy of CBCTs in the presence of sufficient bone thickness, further studies are required to evaluate the accuracy in areas of insufficient bone ${ }^{52}$. Likewise, it has been demonstrated that CBCTs have low accuracy in assessing buccal bone width when the bone thickness is $<0.5 \mathrm{~mm}^{44}$. Although Lago et al. ${ }^{36}$ reported that platform switching may preserve crestal bone levels and maintain soft tissue in esthetic zones, radiographic crestal bone levels are only an indirect measurement of esthetics outcome and thus platform switching does not necessarily directly improve esthetics.

Follow-up periods: Maintenance through follow-up visits is essential. However, a wide range of follow-up visits are reported. Straumann TL implants exhibited minimal changes in MBL during the follow-up periods, among which the maximum follow-up duration was 10 years ${ }^{25}$.

\section{Conclusion}

There are several inconsistencies among studies and methodologies that limit precise comparisons. Bone alterations have been reported in different ways involving mean bone resorption, MBL, percentage of BL change, and the amount of BL change. Therefore, it makes exact comparisons impossible. Multifactorial characteristics of peri-implant bone resorption and diversity among implants and patients leads to a heterogeneity of results and cannot be applied to clinical indications. Clinicians must notice patient demands and 
attempt to choose the most proper implant design based on clinical demands. Researchers should use patients who share common situations such as receiving similar prostheses, requiring augmentation, receiving same implant types, and the rehabilitation of similar edentulous areas to reduce systematic errors and potential bias. Biomaterial-related tissue reactions remain unclarified. The short-term nature of the results, limited sample size, and radiographic measurements of mesial and distal crestal BL changes are several limitations. Therefore, comparative long-term randomized clinical trials and a large number of patients are required.

\section{ORCID}

Hamed Mortazavi, https://orcid.org/0000-0002-0778-5299

Amin Khodadoustan, https://orcid.org/0000-0002-8619-4138

Aida Kheiri, https://orcid.org/0000-0002-5311-1260

Lida Kheiri, https://orcid.org/0000-0001-9471-9902

\section{Authors' Contributions}

H.M. participated in study design and performed analysis. A.K. (Amin Khodadoustan) participated in data collection. A.K. (Aida Kheiri) participated in data collection and wrote the manuscript. L.K. wrote the manuscript. All authors read and approved the final manuscript.

\section{Conflict of Interest}

No potential conflict of interest relevant to this article was reported.

\section{References}

1. Al-Nawas B, Brägger U, Meijer HJ, Naert I, Persson R, Perucchi A, et al. A double-blind randomized controlled trial (RCT) of Titanium-13Zirconium versus Titanium Grade IV small-diameter bone level implants in edentulous mandibles--results from a 1-year observation period. Clin Implant Dent Relat Res 2012;14:896-904. https://doi.org/10.1111/j.1708-8208.2010.00324.x

2. Andreasi Bassi M, Lopez MA, Confalone L, Gaudio RM, Lombardo L, Lauritano D. Clinical outcome of a two-piece implant system with an internal hexagonal connection: a prospective study. J Biol Regul Homeost Agents 2016;30(2 Suppl 1):7-12.

3. Ghazal SS, Huynh-Ba G, Aghaloo T, Dibart S, Froum S, O'Neal R, et al. A randomized, controlled, multicenter clinical study evaluating the crestal bone level change of SLActive Bone Level Ø 3.3 $\mathrm{mm}$ implants compared to SLActive Bone Level Ø $4.1 \mathrm{~mm}$ implants for single-tooth replacement. Int J Oral Maxillofac Implants 2019;34:708-18. https://doi.org/10.11607/jomi.6927

4. Alharbi HM, Babay N, Alzoman H, Basudan S, Anil S, Jansen JA. Bone morphology changes around two types of bone-level implants installed in fresh extraction sockets--a histomorphometric study in Beagle dogs. Clin Oral Implants Res 2015;26:1106-12. https://doi. org/10.1111/clr.12388

5. Chiapasco M, Casentini P, Zaniboni M, Corsi E. Evaluation of peri-implant bone resorption around Straumann Bone Level implants placed in areas reconstructed with autogenous vertical onlay bone grafts. Clin Oral Implants Res 2012;23:1012-21. https://doi. org/10.1111/j.1600-0501.2011.02262.x

6. Puisys A, Linkevicius T. The influence of mucosal tissue thickening on crestal bone stability around bone-level implants. A prospective controlled clinical trial. Clin Oral Implants Res 2015;26:123-9. https://doi.org/10.1111/clr.12301

7. Güven SŞ, Cabbar F, Güler N. Local and systemic factors associated with marginal bone loss around dental implants: a retrospective clinical study. Quintessence Int 2020;51:128-41. https://doi. org/10.3290/j.qi.a42950

8. Wu S, Wu X, Shrestha R, Lin J, Feng Z, Liu Y, et al. Clinical and radiologic outcomes of submerged and nonsubmerged bone-level implants with internal hexagonal connections in immediate implantation: a 5-year retrospective study. J Prosthodont 2018;27:101-7. https://doi.org/10.1111/jopr.12647

9. Donos N, Horvath A, Calciolari E, Mardas N. Immediate provisionalization of bone level implants with a hydrophilic surface. A five-year follow-up of a randomized controlled clinical trial. Clin Oral Implants Res 2019;30:139-49. https://doi.org/10.1111/ clr. 13400

10. Marković A, Čolić S, Šćepanović M, Mišić T, Đinić A, Bhusal DS. A 1-year prospective clinical and radiographic study of earlyloaded bone level implants in the posterior maxilla. Clin Implant Dent Relat Res 2015;17:1004-13. https://doi.org/10.1111/cid.12201

11. Schwarz F, Sager M, Kadelka I, Ferrari D, Becker J. Influence of titanium implant surface characteristics on bone regeneration in dehiscence-type defects: an experimental study in dogs. J Clin Periodontol 2010;37:466-73. https://doi.org/10.1111/j.1600051X.2010.01533.x

12. Cochran DL, Bosshardt DD, Grize L, Higginbottom FL, Jones AA, Jung RE, et al. Bone response to loaded implants with non-matching implant-abutment diameters in the canine mandible. J Periodontol 2009;80:609-17. https://doi.org/10.1902/jop.2009.080323

13. Filippi A, Higginbottom FL, Lambrecht T, Levin BP, Meier JL, Rosen PS, et al. A prospective noninterventional study to document implant success and survival of the Straumann Bone Level SLActive dental implant in daily dental practice. Quintessence Int 2013;44:499-512. https://doi.org/10.3290/j.qi.a29611

14. Elian N, Bloom M, Trushkowsky RD, Dard MM, Tarnow D. Effect of 3- and 4-mm interimplant distances on the height of interimplant bone crest: a histomorphometric evaluation measured on bone level dental implants in minipig. Implant Dent 2014;23:522-8. https:// doi.org/10.1097/ID.0000000000000153

15. Gao E, Hei WH, Park JC, Pang K, Kim SK, Kim B, et al. Bonelevel implants placed in the anterior maxilla: an open-label, singlearm observational study. J Periodontal Implant Sci 2017;47:31227. https://doi.org/10.5051/jpis.2017.47.5.312

16. Canullo L, Fedele GR, Iannello G, Jepsen S. Platform switching and marginal bone-level alterations: the results of a randomizedcontrolled trial. Clin Oral Implants Res 2010;21:115-21. https://doi. org/10.1111/j.1600-0501.2009.01867.x

17. Koutouzis T, Mesia R, Calderon N, Wong F, Wallet S. The effect of dynamic loading on bacterial colonization of the dental implant fixture-abutment interface: an in vitro study. J Oral Implantol 2014;40:432-7. https://doi.org/10.1563/AAID-JOI-D-11-00207

18. Lauritano D, Moreo G, Lucchese A, Viganoni C, Limongelli L, Carinci F. The impact of implant-abutment connection on clinical outcomes and microbial colonization: a narrative review. Materials (Basel) 2020;13:1131. https://doi.org/10.3390/ma13051131

19. Flores-Guillen J, Álvarez-Novoa C, Barbieri G, Martín C, Sanz M. Five-year outcomes of a randomized clinical trial comparing 
bone-level implants with either submerged or transmucosal healing. J Clin Periodontol 2018;45:125-35. https://doi.org/10.1111/ jcpe. 12832

20. Lorenz J, Lerner H, Sader RA, Ghanaati S. Investigation of periimplant tissue conditions and peri-implant tissue stability in implants placed with simultaneous augmentation procedure: a 3 -year retrospective follow-up analysis of a newly developed bone level implant system. Int J Implant Dent 2017;3:41. https://doi. org/10.1186/s40729-017-0104-4

21. Tesmer M, Wallet S, Koutouzis T, Lundgren T. Bacterial colonization of the dental implant fixture-abutment interface: an in vitro study. J Periodontol 2009;80:1991-7. https://doi.org/10.1902/ jop.2009.090178

22. Nóvoa L, Batalla P, Caneiro L, Pico A, Liñares A, Blanco J. Influence of abutment height on maintenance of peri-implant crestal bone at bone-level implants: a 3-year follow-up study. Int J Periodontics Restorative Dent 2017;37:721-7. https://doi.org/10.11607/ $\operatorname{prd} .2762$

23. Santing HJ, Raghoebar GM, Vissink A, den Hartog L, Meijer HJ. Performance of the Straumann Bone Level Implant system for anterior single-tooth replacements in augmented and nonaugmented sites: a prospective cohort study with 60 consecutive patients. Clin Oral Implants Res 2013;24:941-8. https://doi.org/10.1111/j.16000501.2012.02486.x

24. Vanlığlu BA, Kahramanoğlu E, Ozkan Y, Kulak-Özkan Y. Clinical and radiographic evaluation of early loaded maxillary anterior single-tooth bone-level implants. Int J Oral Maxillofac Implants 2014;29:1369-73. https://doi.org/10.11607/jomi.3446

25. Kang MH, Jung UW, Cho KS, Lee JS. Retrospective radiographic observational study of 1692 Straumann tissue-level dental implants over 10 years. II. Marginal bone stability. Clin Implant Dent Relat Res 2018;20:875-81. https://doi.org/10.1111/cid.12636

26. Friedmann A, Gissel K, Soudan M, Kleber BM, Pitaru S, Dietrich T. Randomized controlled trial on lateral augmentation using two collagen membranes: morphometric results on mineralized tissue compound. J Clin Periodontol 2011;38:677-85. https://doi. org/10.1111/j.1600-051X.2011.01738.x

27. Agustín-Panadero R, Martínez-Martínez N, Fernandez-Estevan L, Faus-López J, Solá-Ruíz MF. Influence of transmucosal area morphology on peri-implant bone loss in tissue-level implants. Int J Oral Maxillofac Implants 2019;34:947-52. https://doi. org/10.11607/jomi.7329

28. Makowiecki A, Botzenhart U, Seeliger J, Heinemann F, Biocev P, Dominiak M. A comparative study of the effectiveness of early and delayed loading of short tissue-level dental implants with hydrophilic surfaces placed in the posterior section of the mandible-a preliminary study. Ann Anat 2017;212:61-8. https://doi. org/10.1016/j.aanat.2017.02.009

29. Kumar VV, Sagheb K, Kämmerer PW, Al-Nawas B, Wagner W. Retrospective clinical study of marginal bone level changes with two different screw-implant types: comparison between tissue level (TE) and bone level (BL) implant. J Maxillofac Oral Surg 2014;13:259-66. https://doi.org/10.1007/s12663-013-0532-5

30. Lopez MA, Andreasi Bassi M, Confalone L, Gaudio RM, Lombardo L, Lauritano D. Retrospective study on bone-level and softtissue-level cylindrical implants. J Biol Regul Homeost Agents 2016;30(2 Suppl 1):43-8.

31. Hadzik J, Botzenhart U, Krawiec M, Gedrange T, Heinemann F, Vegh A, et al. Comparative evaluation of the effectiveness of the implantation in the lateral part of the mandible between short tissue level (TE) and bone level (BL) implant systems. Ann Anat 2017;213:78-82. https://doi.org/10.1016/j.aanat.2017.05.008

32. Ladwein C, Schmelzeisen R, Nelson K, Fluegge TV, Fretwurst T. Is the presence of keratinized mucosa associated with periimplant tissue health? A clinical cross-sectional analysis. Int J Implant Dent 2015;1:11. https://doi.org/10.1186/s40729-015-0009-z

33. Wallner G, Rieder D, Wichmann MG, Heckmann SM. Peri-implant bone loss of tissue-level and bone-level implants in the esthetic zone with gingival biotype analysis. Int J Oral Maxillofac Implants 2018;33:1119-25. https://doi.org/10.11607/jomi.6641

34. Canullo L, Menini M, Covani U, Pesce P. Clinical outcomes of using a prosthetic protocol to rehabilitate tissue-level implants with a convergent collar in the esthetic zone: a 3-year prospective study. J Prosthet Dent 2020;123:246-51. https://doi.org/10.1016/ j.prosdent.2018.12.022

35. Buser D, Janner SF, Wittneben JG, Brägger U, Ramseier CA, Salvi GE. 10-Year survival and success rates of 511 titanium implants with a sandblasted and acid-etched surface: a retrospective study in 303 partially edentulous patients. Clin Implant Dent Relat Res 2012;14:839-51. https://doi.org/10.1111/j.1708-8208.2012.00456.x

36. Lago L, da Silva L, Gude F, Rilo B. Bone and soft tissue response in bone-level implants restored with platform switching: a 5 -year clinical prospective study. Int J Oral Maxillofac Implants 2017;32:919-26. https://doi.org/10.11607/jomi.5859

37. Lago L, da Silva L, Martinez-Silva I, Rilo B. Radiographic assessment of crestal bone loss in tissue-level implants restored by platform matching compared with bone-level implants restored by platform switching: a randomized, controlled, split-mouth trial with 3-year follow-up. Int J Oral Maxillofac Implants 2019;34:179-86. https://doi.org/10.11607/jomi.6954

38. Lago L, da Silva L, Martinez-Silva I, Rilo B. Crestal bone level around tissue-level implants restored with platform matching and bone-level implants restored with platform switching: a 5 -year randomized controlled trial. Int J Oral Maxillofac Implants 2018;33:448-56. https://doi.org/10.11607/jomi.6149

39. Fernández-Formoso N, Rilo B, Mora MJ, Martínez-Silva I, DíazAfonso AM. Radiographic evaluation of marginal bone maintenance around tissue level implant and bone level implant: a randomised controlled trial. A 1-year follow-up. J Oral Rehabil 2012;39:830-7. https://doi.org/10.1111/j.1365-2842.2012.02343.x

40. Chiapasco M, Casentini P, Zaniboni M. Implants in reconstructed bone: a comparative study on the outcome of Straumann ${ }^{\circledR}$ tissue level and bone level implants placed in vertically deficient alveolar ridges treated by means of autogenous onlay bone grafts. Clin Implant Dent Relat Res 2014;16:32-50. https://doi.org/10.1111/ j.1708-8208.2012.00457.x

41. Chiapasco M, Casentini P, Zaniboni M, Corsi E, Anello T. Titanium-zirconium alloy narrow-diameter implants (Straumann Roxolid(®)) for the rehabilitation of horizontally deficient edentulous ridges: prospective study on 18 consecutive patients. Clin Oral Implants Res 2012;23:1136-41. https://doi.org/10.1111/j.16000501.2011.02296.x

42. Fretwurst T, Nack C, Al-Ghrairi M, Raguse JD, Stricker A, Schmelzeisen R, et al. Long-term retrospective evaluation of the peri-implant bone level in onlay grafted patients with iliac bone from the anterior superior iliac crest. J Craniomaxillofac Surg 2015;43:956-60. https://doi.org/10.1016/j.jcms.2015.03.037

43. Buser D, Halbritter S, Hart C, Bornstein MM, Grütter L, Chappuis $\mathrm{V}$, et al. Early implant placement with simultaneous guided bone regeneration following single-tooth extraction in the esthetic zone: 12 -month results of a prospective study with 20 consecutive patients. J Periodontol 2009;80:152-62. https://doi.org/10.1902/ jop. 2009.080360

44. Le BT, Borzabadi-Farahani A. Simultaneous implant placement and bone grafting with particulate mineralized allograft in sites with buccal wall defects, a three-year follow-up and review of literature. J Craniomaxillofac Surg 2014;42:552-9. https://doi. org/10.1016/j.jcms.2013.07.026

45. Buser D, Chappuis V, Bornstein MM, Wittneben JG, Frei M, Belser UC. Long-term stability of contour augmentation with early implant placement following single tooth extraction in the esthetic zone: a prospective, cross-sectional study in 41 patients with a 5to 9-year follow-up. J Periodontol 2013;84:1517-27. https://doi. org/10.1902/jop.2013.120635 
46. Shin YK, Han CH, Heo SJ, Kim S, Chun HJ. Radiographic evaluation of marginal bone level around implants with different neck designs after 1 year. Int J Oral Maxillofac Implants 2006;21:78994.

47. Vianna TT, Taiete T, Casarin RCV, Giorgi MCC, Aguiar FHB, Silvério $\mathrm{KG}$, et al. Evaluation of peri-implant marginal tissues around tissue-level and bone-level implants in patients with a history of chronic periodontitis. J Clin Periodontol 2018;45:1255-65. https:// doi.org/10.1111/jcpe.12999

48. Sargolzaie N, Samizade S, Arab H, Ghanbari H, Khodadadifard L, Khajavi A. The evaluation of implant stability measured by resonance frequency analysis in different bone types. J Korean Assoc Oral Maxillofac Surg 2019;45:29-33. https://doi.org/10.5125/ jkaoms.2019.45.1.29

49. Schrott A, Riggi-Heiniger M, Maruo K, Gallucci GO. Implant loading protocols for partially edentulous patients with extended edentulous sites--a systematic review and meta-analysis. Int J Oral Maxillofac Implants 2014;29 Suppl:239-55. https://doi. org/10.11607/jomi.2014suppl.g4.2

50. Lorenz J, Kubesch A, Korzinskas T, Barbeck M, Landes C, Sader RA, et al. TRAP-positive multinucleated giant cells are foreign body giant cells rather than osteoclasts: results from a split-mouth study in humans. J Oral Implantol 2015;41:e257-66. https://doi. org/10.1563/aaid-joi-D-14-00273

51. Degidi M, Piattelli A, Carinci F. Clinical outcome of narrow diameter implants: a retrospective study of 510 implants. J Periodontol 2008;79:49-54. https://doi.org/10.1902/jop.2008.070248

52. González-Martín O, Oteo C, Ortega R, Alandez J, Sanz M, Veltri M. Evaluation of peri-implant buccal bone by computed tomography: an experimental study. Clin Oral Implants Res 2016;27:950-5. https://doi.org/10.1111/clr.12663

How to cite this article: Mortazavi $\mathrm{H}$, Khodadoustan A, Kheiri A, Kheiri L. Bone loss-related factors in tissue and bone level dental implants: a systematic review of clinical trials. J Korean Assoc Oral Maxillofac Surg 2021;47:153-174. https://doi.org/10.5125/ jkaoms.2021.47.3.153 